\title{
Job Stress, Involvement, Satisfaction and Performance of Employees in Garment 10 Corporation in Vietnam
}

\author{
Viet Duc Than ${ }^{1}$, Cuong Hung Pham ${ }^{2} \&$ Long Pham ${ }^{3}$ \\ ${ }^{1}$ Garment 10 Corporation, Vietnam \\ ${ }^{2}$ Foreign Trade University, Ho Chi Minh City Campus, Vietnam \\ ${ }^{3}$ National Economics University, Vietnam \\ Correspondence: Cuong Hung Pham, Foreign Trade University, Ho Chi Minh City Campus, \#15D5, Ward 25, Binh \\ Thanh District, Ho Chi Minh City, Vietnam.
}

Received: April 9, 2016

Accepted: May 4, 2016

Online Published: May 13, 2016

doi:10.5430/ijfr.v7n3p96

URL: http://dx.doi.org/10.5430/ijfr.v7n3p96

\begin{abstract}
Up to now, a great deal of literature has identified key factors influencing employee performance in developed countries - North America and Europe and to a lesser extent in other regions including a mix of developed and developing countries, such as Singapore, Taiwan, Malaysia, and Thailand. To put it another way, little research on factors influencing employee performance has been implemented in countries that are emerging as new potential markets with very high economic growth rates. Among these countries is Vietnam where its average economic growth rate (GDP) was over 7\% during the 1990s and early 2000s, and especially more than $8 \%$ in $2006-2008$, which made it one of the highest growing economies in the World. Together with Vietnam's entry into the World Trade Organization dated on 7 November 2006, its companies are increasingly developing in accordance with the requirements set up by the World Trade Organization. These moves suggest that fierce competition among local and foreign companies in Vietnam, especially in the garment field. However, there are no comprehensive models or frameworks to explain the employee performance in garment field in Vietnam. This study has based on an extensive review of literature on employee satisfaction, employee commitment, job involvement, and job stress proposed a comprehensive model for employee performance in garment company 10. Furthermore, a set of model hypotheses presenting relationships among these factors have been set up. The model presented in this paper is unique as at present, there is no comprehensive theoretical and practical model for analyzing employee performance in the garment field in newly emerging countries such as Vietnam. None of the prior models have taken into account the linear and non-linear relationships among these factors to investigate employee performance in the garment field. We utilized the structural equation technique to test the hypotheses (linear and non-linear) and found that four of the seven hypothesized relationships were found to be statistically significant. Specifically, employee performance was most significantly influenced by job involvement $\left(\mathrm{\gamma}_{2}=0.365, p<0.01\right)$, followed by job stress $\left(\mathrm{\gamma}_{5}=-0.347, p<\right.$ $0.01)$, and normative commitment $\left(\mathrm{\gamma}_{4}=0.226, p<0.05\right)$. Also, the relationship between job satisfaction and employee performance was found to be significantly positive moderated by affective commitment $\left(\mathrm{\gamma}_{6}=0.158, p<\right.$ 0.05 ). Our study provides comprehensive implications that can be benchmarked by many garment companies in Vietnam. The companies may implement management policies in general and marketing policies in particular to increase levels of job involvement, employee commitment, and reduce job stress. Specifically, the companies should provide opportunities and necessary resources for employees in order to escalate their performance.
\end{abstract}

Keywords: job stress, involvement, satisfaction and performance of employees, Garment 10 Corporation

\section{Introduction}

Since the late $19^{\text {th }}$ century there has been an increased interest in factors that distinguish functional organizations from successful organizations. For years, researchers sought to explain organizational success by the value of a company's stock portfolio, administrative structure and organizational chart. Most recently, organizations have begun to take a closer look at interpersonal factors that may impact workforce dynamics and productivity (Somech \& Ron, 2007). Moreover, they have begun to examine people power and the role it plays in organizational networks. Researchers have sought to discover which variables have the greatest impact, if any, on organizational outcomes. Researchers have discovered that no single attribute or attitudinal variable thus far can explain the dynamics of 
employee organizational commitment (Caselman \& Brandt, 2007). Social exchanges in the workplace have a direct impact on workplace outcomes such as employee turnover. Organizations continue to seek answers regarding employee workplace and citizenship behaviors (Joiner \& Bakalis, 2006). However, it will be necessary for them to gain further insight into the quality and characteristics of workforce interactions and relationships. Not only are peer subordinate relationship interactions important, but also the quality of interaction between a supervisor and a subordinate. Past studies indicated that the quality of the supervisor subordinate relationship is very important because supervisors perform as an organizational agent helping to facilitate the goals of the organization on the most interactive level. Another factor related to organizational commitment that has also recently received attention is the relationship that subordinates share with each other. Specifically, supportive work groups have been reported to help clarify job roles, decrease role ambiguity, provide social and moral support, and provide opportunities for positive work experiences (Abbott et al., 2006). Employees who are satisfied with their work environment, and are involved in additional work duties are also likely to report higher work commitment. Employees who are dissatisfied with their employment only complete the minimum workplace duties (Chen \& Hung, 2006). The extent literature is limited regarding organizational commitment in garment settings. Strict attention was needed to examine specific antecedents and consequences among garment employees including: job stress, job satisfaction, level of work involvement, organizational support, employee performance (Joiner \& Bakalis, 2006). It was hypothesized that there is a significant relationship between job satisfaction, job involvement, job stress, perceived organizational support, employee commitment and performance.

\section{Literature Review}

Job stress is a major workplace concern and the focus of many organizational researchesr (Fox \&Spector, 2006). Situations that create strees, such as downsizing, technology, violence, are part of the current business environment (DeFrank \& Ivancevich, 1998). Further sources of stress in the workplace include work overload, incompetent supervisors, role ambiguity, and lack of recognition, among others. According to Dwyer and Ganster (1991), it is a wide and popularly accepted proposition that stressfull work conditions generate significant costs in terms of low productivity, sickness, and lost time. DeFrank and Ivancevich (1998) found that, in 1990 stress related claims become the fastest growing segment of the Workers Compensation System.

While there is much disagreement among reserachers on defing stress, there is a need to clearly define this construct for the purposes of this study. Having gone through the different perspectives and arguments and the empirical work that was used to support them, this reseracher defines job stress as a process that involves stressors, that is any organizational event or condition that an individual evaluates as negative or threatening, and strain, the resultant effects of the negative or threatening event on the individual. According to this theoretial assumption job stress is the super construct and time stress (stressor) and anxiety (strain) are subconstructs of job stress.

Stress is defined as "a state of worry that arises from an actual or apparent demand that calls an change behavior" (Lazarus, 1999). Stress generally has been familiar as an disagreeable emotional condition, which is said to occur when there have been extended, increasing or new force that are significantly greater than the coping resources (Siegrist, 2001). The penalty of stress include health harms and reduction in work success.

Job satisfaction had been one of the most important topics that was studied by the organization behaviors researcher during last decades. Job satisfaction defined by (Robbin, Millett \& Marh, 2004) as "apposition feeling about one's job that results from an evaluation of its characteristics" and this means that a person who holds positive attitude and feeling about the job is highly satisfied than the person who shows more negative attitude and feeling about the job. In the late of 1970's, Locke set a new definition for job satisfaction and he redefined it as "an internal state which refers to an employee's overall sense of well-being at work". Usually in the literatures, job satisfaction linked to work performance and employee's productivity as well as it linked to other work important issues such as turnover and absenteeism (Zhang, Yao and Cheong, 2010).

Job satisfaction is one of the most researched variables in organizational behavior research (Heller, Judge \& Watson, 2002). It is termed by some organizational researchers as the pivotal construct in organizational behavior. Job satisfaction is also one of the most debated constructs in organizational research. In an effort to elaborate upon the theories that underlie the job satisfaction construct and the possible causes and effects of job satisfaction, a review and critique of foundational studies on job satisfaction is presented below.

Vroom (1964) defined job satisfaction as one's atiitude towards work. According to Vroom (1964), "positive attitudes toward the job are conceptually equivalent to job satisfaction...". That is, if a person is positively oriented towards his/her work roles, he/she is dissatisfied with the job. Vroom (1964) used his valence-expectancy theory to support this assumption. Valence is "an individual's preference for a particular outcome or "affective orientations 
toward particular outcome". The individual's behavior is affected by both, the preference for the outcome and the probability of this preference leading to a higher benefit. The latter is "the degree to which he or she believes these outcomes to be probable", and the belief that a particular outcome will reap benefits is expectancy. The individual is satisfied if the expectancy is met. Loker (1976) in criticizing Vroom's (1964) theory, pointed out that it fails to differentiate "the amount of value wanted by the person and how much the person wants that amount"). The volume of the value (how much) and the degree of importance (how important) has to distinguishable in order to accurately measure job satisfaction.

Locke (1976), in his definition of job satisfaction, described it as a result of “...the appraisal of one's job as attaining or allowing the attainment of one's important job values, providing these values are congruent with or help to fulfill one's basic needs...". The main charcteristics of Locke's (1976) definition are that a person appraises his/her job based on how it measures up to his/her job values and that these job values stem from one's basics needs. Although the appraisal process could be implicit in Vroom's (1964) definition, Locke (1976) suggested these two levels in the job satisfaction process: job values stem from a person's basic needs and the attainment of the job values are equivalent to being satisfied with the job. Thus job satisfaction is an outcome on account of one's appraisal based on the attainment of job values that are important to the person. It is also important to point out that in one of Lock's (1976) initial description of job satisfaction he termed it “... a positive emotional state resulting from the appraisal of one's job...". This definition of job satisfaction overlaps with similar terms used by Lazarus (1991) to explain emotions such as anxiety and anger, and the appraisal process. Spector (1997), based on more recent studies, defined job satisfaction as an "attitudinal perspective". According to Spector, more recent researchers believe job satisfaction to be based on cognitive processes and not on needs. The need-based approach, as mentioned previously, was suggested by Locke (1976).

\section{Research Method}

Organizational commitment has been identified as a leading factor impacting the level of success in many organizations (Meyer \& Allen, 1993). This study examined the relationship between job satisfaction, job involvement, job stress and commitment as predictors of employee performance. In recent years, organizations have acknowledged that their workforce can only be as successful as their best organizational leaders and the employees who work under their relationship. There is little evidence in the literature that identified specific factors that impact organizational commitment among employees in the garment field (Chang \& Choi, 2007).

Based on an integration of job stress, involvement, satisfaction, commitment and performance, a conceptual model is built in Figure 1.

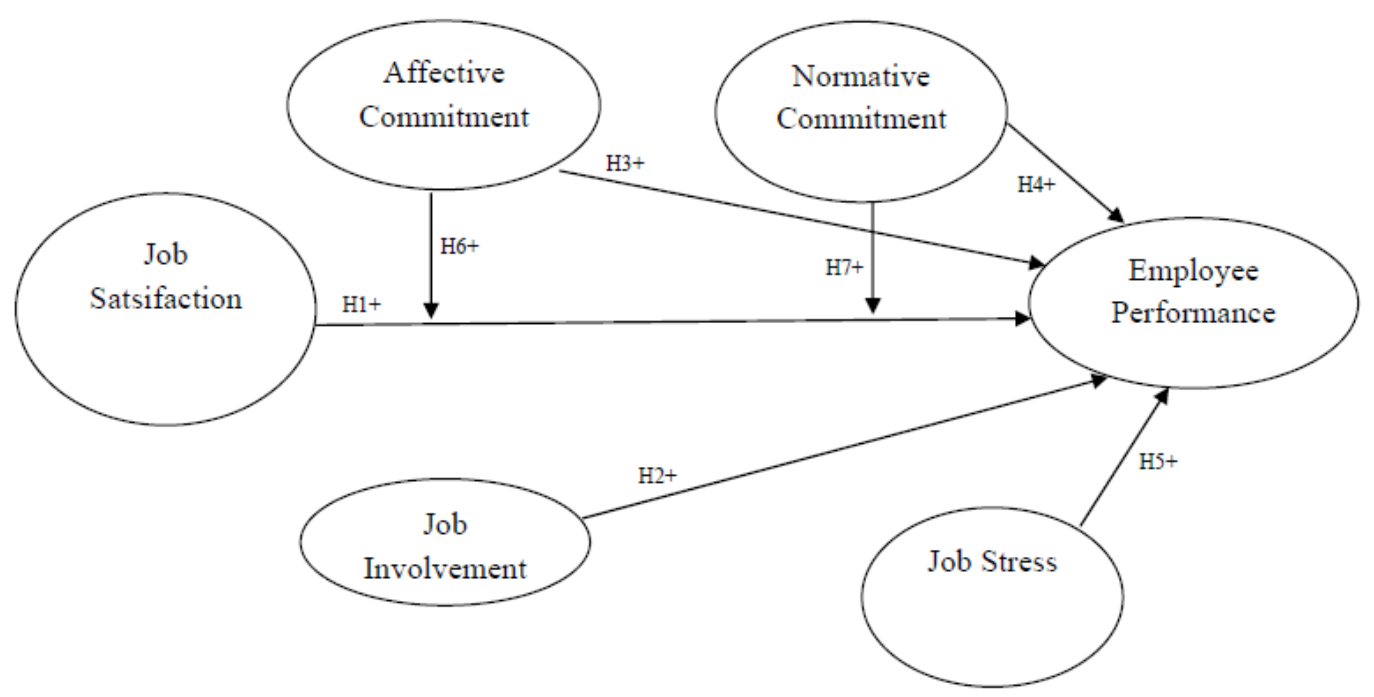

Figure 1. The research model

H1. Job satisfaction will have a positive direct relationship with employee peformance.

H2. Job involvement will have a positive direct relationship with employee peformance.

H3. Affective commitment will have a positive direct relationship with employee peformance. 
H4. Normative commitment will have a positive direct relationship with employee peformance.

H5. Job stress will have a negative direct relationship with employee peformance.

H6. The relationship between job satisfaction and employee performance will be positively moderated by affective commitment.

H7. The relationship between job satisfaction and employee performance will be positively moderated by normative commitment.

The research hypotheses can be integrated to form a set of structural equations. The following abbreviations are used for simplicity: job satisfaction (JS), job involvement (JI), affective commitment (AC), normative commitment (NC), job stress (JST), and employee performance (EP). So, Model can be represented as:

\section{Research Results}

$$
\mathrm{EP}=\mathrm{\gamma}_{1}(\mathrm{JS})+\mathrm{\gamma}_{2}(\mathrm{JI})+\mathrm{\gamma}_{3}(\mathrm{AC})+\mathrm{\gamma}_{4}(\mathrm{NM})+\mathrm{\gamma}_{5}(\mathrm{JST})+\mathrm{\gamma}_{6}(\mathrm{JS}) *(\mathrm{AC})+\mathrm{\gamma}_{7}(\mathrm{JS}) *(\mathrm{NC})+\zeta_{2}
$$

Measurement model. First, we tested the preliminary measurement model, using a confirmatory factor analysis of the scales. The result indicated that 18 items were not properly loaded in the measurement model due to unacceptably low factor loadings less than 0.5 , large measurement errors greater than 3.0 in absolute value, and/or a high level of cross-loadings manifested by the Lagrange Multiplier (LM) test (Bentler, 1995). Consequently, the 18 items were deleted from the measurement model. The revised measurement model is illustrated in the following figure:

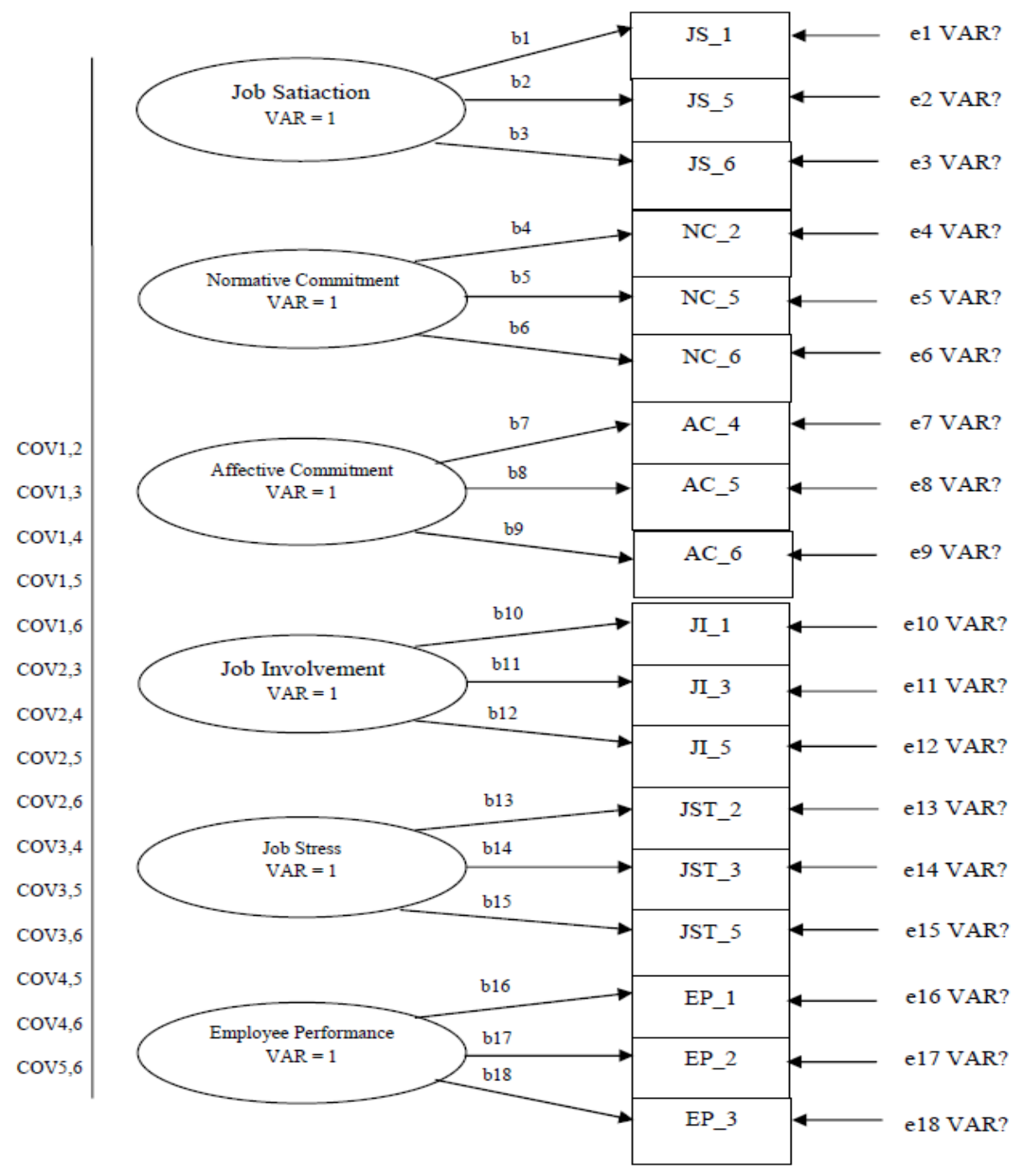

Figure 2. The measurement model 
For the measurement model (CFA - confirmatory factor analysis), latent variables are allowed to correlate with each other and variance of each latent variable is set equal to 1 to overcome the problem of different measurement units. Thus, there are 18 factor loadings (regression coefficients between latent variables and indicators), 18 residual variances, and 15 covariances among latent variables that need to be estimated.

Model identification. Once a confirmatory factor model has been specified, the next step is to determine whether the model is identified. It is crucial that the researcher solve the identification problem prior to the estimation of parameters. In model identification, we ask the following question: On the basis of the sample data contained in the sample variance-covariance matrix $\mathrm{S}$, and the hypothesized theoretical model, can a unique set of parameter estimates for the population variance-covariance matrix $\sum$ be found? For our confirmatory factor model, we would like to know if the factor loading of JS_1 on job satisfaction, JS_5 on job satisfaction, JS_6 on job satisfaction, NC_2 on normative commitment, $\mathrm{NC} \_5$ on normative commitment, $\mathrm{NC}_{-} 6$ on normative commitment, $\mathrm{AC} \_4$ on affective commitment, AC_5 on affective commitment, AC_6 on affective commitment, JI_1 on job involvement, JI_3 on job involvement, JI_5 on job involvement, JST_ 2 on job stress, JST_ 3 on job stress, JST_5 on job stress, EP_1 on employee performance, EP_2 on employee performance, and EP_3 on employee performance are identified (can be estimated). The number of free parameters to be estimated must be less than or equal to the number of distinct values in the matrix S. A count of the free parameters is as follows:

18 factor loadings

18 measurement error variances

Zero measurement error covariances

15 covariances among the latent variables

Thus there is a total of 51 free parameters that we wish to estimate. The number of distinct values in the matrix $\mathrm{S}$ is equal to

$$
\mathrm{p}(\mathrm{p}+1) / 2=18(18+1) / 2=171,
$$

where $\mathrm{p}$ is the number of variables in the sample variance-covariance matrix for the observed (indicator) variables. The number of values in S, 171, is greater than the number of free parameters, 51, with the difference being the degrees of freedom for the specified model, $\mathrm{df}=171-51=120$. However, this is only a necessary condition and does not guarantee that the model is identified. According to the order condition, this model is overidentified because there are more values in $\mathrm{S}$ than parameters to be estimated, that is, our degrees of freedom is positive rather than zero (just-identified) or negative (underidentified). The sufficient conditions require us to algebraically determine whether each parameter in the model can be estimated from the covariance matrix S. Mplus check on this to make sure that the confirmatory factor model is identified.

Model testing. An important part of the estimation process in analyzing confirmatory factor models is to fit the sample variance-covariance data to the specified model. If the fit of the model is good, then the specified model is supported by the sample data. If the fit of the model is poor, then the specified model is not supported by the sample data. There is a wide variety of model fit indices available to the applied SEM researcher.

The following are codes of Mplus for testing the above measurement model:

Variables: Names are JS_1 JS_5 JS_6

$$
\begin{aligned}
& \text { NC_2 NC_5 NC_6 } \\
& \text { AC_4 AC_5 AC_6 } \\
& \text { JI_1 JI_3 JI_5 } \\
& \text { JST_2 JST_3 JST_5 } \\
& \text { EP_1 EP_2 EP_3; }
\end{aligned}
$$

Model: f1 by JS_1 JS_5 JS_6;

$$
\text { f2 by NC_2 NC_5 NC_6; }
$$$$
\text { f3 by AC_4 AC_5 AC_6; }
$$$$
\text { f4 by JI_1 JI_3 JI_5; }
$$$$
\text { f5 by JST_2 JST_3 JST_5; }
$$$$
\text { f6 by EP_1 EP_2 EP_3; }
$$ 
Output: standardized;

That is, perceived benefit is measured by 3 indicators JS_1, JS_5, and JS_6, so the code is written as f1 by JS_1 JS_5 JS_6 and the same things for $\mathrm{f} 2, \mathrm{f3}, \mathrm{f4}, \mathrm{f5}$, and f6. Variances are implicitly set equal to 1 in Mplus. The parameters which will be estimated are factor loadings (between each latent variable and its indicators), covariances among latent variables, and residual variances.

The following are results of testing the measurement model by utilizing Mplus:

Table 1. Parameters estimated

\begin{tabular}{|c|c|}
\hline Mplus output & \\
\hline Parameter estimated & Value \\
\hline F1 by JS_1 & 0.729 \\
\hline F1 by JS 5 & 0.920 \\
\hline F1 by JS_6 & 0.848 \\
\hline F2 by NC_ 2 & 0.785 \\
\hline F2 by NC_ 5 & 0.897 \\
\hline F2 by NC_6 & 0.754 \\
\hline F3 by $\mathrm{AC}_{-} 4$ & 0.681 \\
\hline F3 by $\mathrm{AC} 5$ & 0.897 \\
\hline $\mathrm{F} 3$ by $\mathrm{AC} 6$ & 0.945 \\
\hline F4 by JI 1 & 0.766 \\
\hline F4 by JI 3 & 0.811 \\
\hline F4 by JI_5 & 0.963 \\
\hline F5 by JST_ 2 & 0.793 \\
\hline F5 by JST 3 & 0.890 \\
\hline F5 by JST_5 & 0.739 \\
\hline F6 by EP_1 1 & 0.865 \\
\hline F6 by EP 2 & 0.861 \\
\hline F6 by EP 3 & 0.822 \\
\hline F1 with F2 & 0.472 \\
\hline F1 with F3 & 0.469 \\
\hline F1 with F4 & 0.484 \\
\hline F1 with F5 & 0.551 \\
\hline F1 with F6 & 0.582 \\
\hline F2 with F3 & 0.388 \\
\hline F2 with F4 & 0.514 \\
\hline F2 with F5 & 0.407 \\
\hline F2 with F6 & 0.610 \\
\hline F3 with F4 & 0.529 \\
\hline F3 with F5 & 0.580 \\
\hline F3 with F6 & 0.569 \\
\hline F4 with F5 & 0.315 \\
\hline F4 with F6 & 0.668 \\
\hline F5 with F6 & 0.584 \\
\hline JS_1 (Residual variances) & 0.468 \\
\hline JS 5 (Residual variances) & 0.154 \\
\hline JS_6 (Residual variances) & 0.280 \\
\hline NC_2 (Residual variances) & 0.384 \\
\hline NC_5 (Residual variances) & 0.196 \\
\hline NC_6 (Residual variances) & 0.431 \\
\hline AC_4 (Residual variances) & 0.536 \\
\hline AC_5 (Residual variances) & 0.196 \\
\hline
\end{tabular}




\begin{tabular}{ll}
\hline AC_6 (Residual variances) & 0.107 \\
\hline JI_1 (Residual variances) & 0.413 \\
\hline JI_3 (Residual variances) & 0.342 \\
\hline JI_5 (Residual variances) & 0.073 \\
\hline JST_2 (Residual variances) & 0.372 \\
\hline JST_3 (Residual variances) & 0.208 \\
\hline JST_5 (Residual variances) & 0.454 \\
\hline EP_1 (Residual variances) & 0.251 \\
\hline EP_2 (Residual variances) & 0.259 \\
\hline EP_3 (Residual variances) & 0.325 \\
\hline
\end{tabular}

The following table summarizes fit values offered by Mplus:

Table 2. Fit summary (Mplus codes)

\begin{tabular}{|c|c|c|c|}
\hline \multirow{3}{*}{$\begin{array}{l}\text { Number of Free Parameters } \\
\text { Loglikelihood }\end{array}$} & & \multicolumn{2}{|l|}{69} \\
\hline & H0 Value & \multicolumn{2}{|l|}{-3831.068} \\
\hline & H1 Value & \multicolumn{2}{|l|}{-3702.742} \\
\hline \multirow[t]{3}{*}{ Information Criteria } & Akaike (AIC) & \multicolumn{2}{|l|}{7800.135} \\
\hline & Bayesian (BIC) & \multicolumn{2}{|l|}{8015.689} \\
\hline & Sample-Size Adjusted BIC & \multicolumn{2}{|l|}{7797.220} \\
\hline \multirow[t]{3}{*}{ Chi-Square Test of Model Fit } & Value & \multicolumn{2}{|l|}{256.651} \\
\hline & Degrees of Freedom & \multirow{2}{*}{\multicolumn{2}{|c|}{$\begin{array}{l}120 \\
0.0000\end{array}$}} \\
\hline & P-Value & & \\
\hline \multirow{3}{*}{$\begin{array}{l}\text { RMSEA (Root Mean Square Error of } \\
\text { Approximation) }\end{array}$} & Estimate & 0.082 & \multirow{3}{*}{0.096} \\
\hline & 90 Percent C.I. & 0.068 & \\
\hline & Probability RMSEA $<=.05$ & 0.000 & \\
\hline \multirow[t]{2}{*}{$\mathrm{CFI} / \mathrm{TLI}$} & CFI & \multicolumn{2}{|l|}{0.934} \\
\hline & TLI & \multicolumn{2}{|l|}{0.915} \\
\hline \multirow{3}{*}{$\begin{array}{l}\text { Chi-Square Test of Model Fit for the } \\
\text { Baseline Model }\end{array}$} & Value & \multicolumn{2}{|l|}{2214.531} \\
\hline & Degrees of Freedom & \multicolumn{2}{|l|}{153} \\
\hline & P-Value & \multicolumn{2}{|l|}{0.0000} \\
\hline $\begin{array}{lll}\text { SRMR (Standardized Root } & \text { Mean } \\
\text { Square Residual) } & & \\
\end{array}$ & Value & \multicolumn{2}{|l|}{0.066} \\
\hline
\end{tabular}

Specifically, $\chi^{2}(120, \mathrm{~N}=168)=256.651$ for Mplus; root mean square error of approximation (RMSEA) $=0.082$ for Mplus; comparative fit index (CFI) $=0.934$ for Mplus, Tucker-Lewis fit index (TLI, also called the non-normed fit index, or NNFI) $=0.915$ for Mplus; standardized root mean square residual $($ SRMR) $=0.066$ for Mplus .

\section{Hypothesized structural model}

As mentioned in the section of formal representation of structural model:

$$
\mathrm{EP}=\mathrm{\gamma}_{1}(\mathrm{JS})+\mathrm{\gamma}_{2}(\mathrm{JI})+\mathrm{\gamma}_{3}(\mathrm{AC})+\mathrm{\gamma}_{4}(\mathrm{NC})+\mathrm{\gamma}_{5}(\mathrm{JST})+\mathrm{\gamma}_{6}(\mathrm{AC}) *(\mathrm{JS})+\mathrm{\gamma}_{7}(\mathrm{NC}) *(\mathrm{JS})+\text { Error }
$$




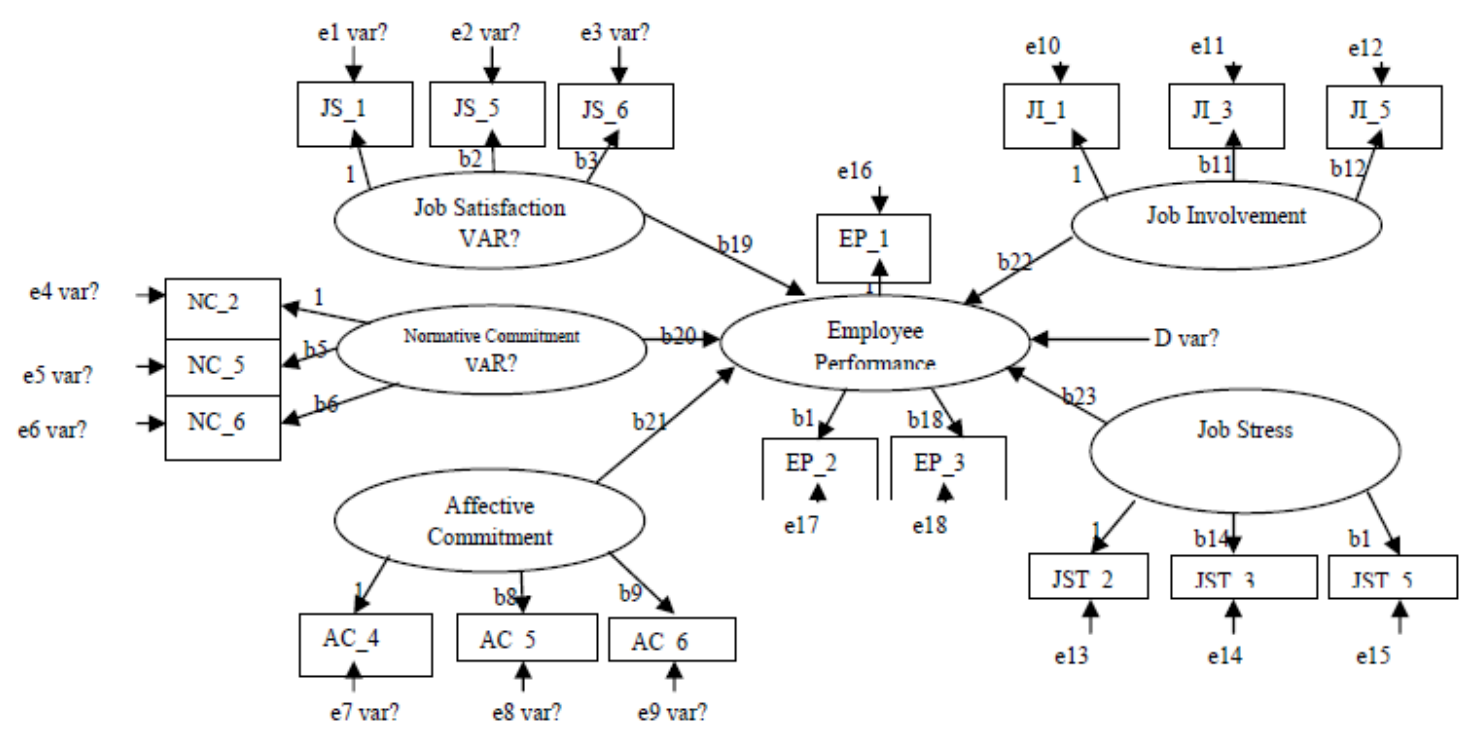

Figure 3. The structural model

Model identification. Once a structural equation model has been specified the next step is to determine whether the model is identified. For the identification problem, we ask the following question: On the basis of the sample data contained in the sample variance-covariance matrix $S$ and the theoretical model implied by the population variance-covariance matrix $\sum$, can a unique set of parameter estimates be found? Specifically, we would like to know whether the factor loadings, measurement errors, structure coefficients, and prediction errors can be estimated (identified). In our model, we fixed certain parameters to resolve the origin and unit of measurement problem while leaving other parameters free to be estimated.

We determine model identification by first checking the order condition. The number of free parameters to be estimated must be less than or equal to the number of distinct values in the matrix S. A count of the free parameters is as follows:

10 factors loadings (with 6 other factor loadings fixed to 1 )

18 measurement error variances

Zero measurement error covariances

5 latent independent variable variances

10 latent independent variable covariances

5 structure coefficients

One equation prediction error variance (Dvar)

There is a total of 49 free parameters in our structural model that we want to estimate. The number of distinct values in the matrix $S$ is equal to $p(p+1) / 2=18(18+1) / 2=171$, where $p$ is the number of observed variables in the sample variance-covariance matrix. The number of values in S, 171, is greater than the number of free parameters, 49 , so the model is probably identified, so we should be able to estimate the number of parameters we want. The degrees of freedom for our structural model is the difference between the number of distinct values in the matrix $\mathrm{S}$ and the number of free parameters we want to estimate, $\mathrm{df}=171-49=122$.

According to the order condition, this model is overidentified because there are more values in $\mathrm{S}$ than parameters to be estimated, that is, our degrees of freedom is positive rather than zero (just-identified) or negative (underidentified). The sufficient conditions require us to algebraically determine whether each parameter in the model can be estimated from the covariance matrix S. Mplus check on this to make sure that the confirmatory factor model is identified.

Model testing. Model testing is the next crucial step in interpreting our results for the hypothesized structural model. When the model fit indices are acceptable, the hypothesized structural model has been supported by the sample variance-covariance data. The model fit indices will be mentioned later. 
* Mplus codes:

Variables: Names are JS_1 JS_5 JS_6

$$
\begin{aligned}
& \text { NC_2 NC_5 NC_6 } \\
& \mathrm{AC} \text { 4 } \mathrm{AC} \text {-5 AC_6 } \\
& \text { JI_1 JI_3 JI_5 } \\
& \text { JST_2 JST_3 JST_5 } \\
& \text { EP_1 EP_2 EP_3; }
\end{aligned}
$$

Model: f1 by JS_1@1 JS_5 JS_6;

f2 by NC_2@1 NC_5 NC_6;

f3 by AC_4@1 AC_5 AC_6;

f4 by JI_1@1 JI_3 JI_5;

f5 by JST_2@1 JST_3 JST_5;

f6 by EP_1@1 EP_2 EP_3;

$\mathrm{f} 6$ on f1 f2 f3 f4 f5;

Output: standardized;

The symbol @ following by 1 indicates that the factor loading is set equal 1. By default, Mplus allows variances and

\begin{tabular}{|c|c|}
\hline \multicolumn{2}{|l|}{ Mplus output } \\
\hline Parameter estimated & Value \\
\hline F1 by JS_1 & 0.729 \\
\hline F1 by JS 5 & 0.920 \\
\hline F1 by JS 6 & 0.848 \\
\hline $\mathrm{F} 2$ by NC 2 & 0.785 \\
\hline $\mathrm{F} 2$ by $\mathrm{NC} 5$ & 0.897 \\
\hline $\mathrm{F} 2$ by NC_6 & 0.754 \\
\hline $\mathrm{F} 3$ by $\mathrm{AC} 4$ & 0.681 \\
\hline F3 by $\mathrm{AC} 5$ & 0.897 \\
\hline $\mathrm{F} 3$ by $\mathrm{AC} \_6$ & 0.945 \\
\hline F4 by JI_1 & 0.766 \\
\hline F4 by JI_3 & 0.811 \\
\hline F4 by JI_5 & 0.963 \\
\hline F5 by JST_2 & 0.793 \\
\hline F5 by JST_3 & 0.890 \\
\hline F5 by JST 5 & 0.739 \\
\hline F6 by EP_1 & 0.865 \\
\hline F6 by EP 2 & 0.861 \\
\hline F6 by EP 3 & 0.822 \\
\hline F6 on F1 & 0.110 \\
\hline F6 on F2 & 0.228 \\
\hline F6 on F3 & 0.076 \\
\hline F6 on F4 & 0.372 \\
\hline F6 on F5 & -0.269 \\
\hline F1 with F2 & 0.472 \\
\hline
\end{tabular}
covariances of independent latent variables to be estimated, and the disturbance relating to the dependent latent variable to be estimated.

The following are results of testing the structural model by utilizing Mplus:

Table 4. Parameter estimated in the structural model 


\begin{tabular}{ll}
\hline F1 with F3 & 0.469 \\
\hline F1 with F4 & 0.484 \\
\hline F1 with F5 & 0.551 \\
\hline F2 with F3 & 0.388 \\
\hline F2 with F4 & 0.514 \\
\hline F2 with F5 & 0.407 \\
\hline F3 with F4 & 0.529 \\
\hline F3 with F5 & 0.580 \\
\hline F4 with F5 & 0.316 \\
\hline JS_1 (Residual variances) & 0.468 \\
\hline JS_5 (Residual variances) & 0.154 \\
\hline JS_6 (Residual variances) & 0.280 \\
\hline NC_2 (Residual variances) & 0.384 \\
\hline NC_5 (Residual variances) & 0.196 \\
\hline NC_6 (Residual variances) & 0.431 \\
\hline AC_4 (Residual variances) & 0.536 \\
\hline AC_5 (Residual variances) & 0.196 \\
\hline AC_6 (Residual variances) & 0.107 \\
\hline JI_1 (Residual variances) & 0.413 \\
\hline JI_3 (Residual variances) & 0.342 \\
\hline JI_5 (Residual variances) & 0.073 \\
\hline JST_2 (Residual variances) & 0.372 \\
\hline JST_3 (Residual variances) & 0.208 \\
\hline JST_5 (Residual variances) & 0.454 \\
\hline EP_1 (Residual variances) & 0.251 \\
\hline EP_2 (Residual variances) & 0.259 \\
\hline EP_3 (Residual variances) & 0.325 \\
\hline Variance F1 & 1 \\
\hline Variance F2 & 1 \\
\hline Variance F3 & 1 \\
\hline Variance F4 & 1 \\
\hline Variance F5 & 1 \\
\hline F6 (Residual variances) & 0.347 \\
\hline &
\end{tabular}

The RMSEA is 0.082 , indicating a "reasonable fit". The ratio of Chi-square to the degrees of freedom is 2.13 , and all other fit indices exceed the suggested threshold values (CFI $=0.934>0.90$; TLI $=0.915>0.90)$, indicating that the tested Model is a sound structural Model. Furthermore, it was found that all the path coefficients (standardized) between employee performance (EP) and job satisfaction (JS), between employee performance (EP) and job involvement (JI), between employee performance (EP) and affective commitment (AC), between employee performance (EP) and normative commitment (NC) are positive, and between employee performance (EP) and job stress (JST) - is negative. Specifically, for Model $1, \gamma_{1}=0.110 ; \gamma_{2}=0.372 ; \gamma_{3}=0.076 ; \gamma_{4}=0.228 ; \gamma_{5}=-0.269$. However, only $\gamma_{2}, \gamma_{4}$, and $\gamma_{5}$ are statistically significant $\left(p<0.01\right.$ ), and among $\gamma_{2}(\mathrm{JI}), \gamma_{4}(\mathrm{NC})$, and $\gamma_{5}$ (JST), job involvement makes largest contribution to employee performance $\left(\mathrm{\gamma}_{2}=0.372\right)$, followed by job stress $\left(\mathrm{\gamma}_{5}=-0.269\right)$ and normative commitment $\left(\mathrm{\gamma}_{2}=0.228\right)$.

\section{Using Mplus to analyze Model 2 (Interaction Effects)}

* Mplus codes for Model 2:

Variables: Names are JS_1 JS_5 JS_6

$$
\begin{aligned}
& \mathrm{NC} \_2 \mathrm{NC} \_5 \mathrm{NC} 66 \\
& \mathrm{AC} \_4 \mathrm{AC} \_5 \mathrm{AC} 66 \\
& \mathrm{JI} \text { 1 JI_3 JI_5 } \\
& \text { JST_2 JST_3 JST_5 } \\
& \text { EP_1 EP_2 EP_3; }
\end{aligned}
$$


Analysis: Type $=$ Random;

Algorithm = Integration

Model: f1 by JS_1@1 JS_5 JS_6;

f2 by NC_2@1 NC_5 NC_6;

f3 by AC_4@1 AC_5 AC_6;

f4 by JI_1@1 JI_3 JI_5;

f5 by JST_2@1 JST_3 JST_5;

f6 by EP_1@1 EP_2 EP_3;

f3xf1 | f3 xwith f1;

f2xf1 | f2 xwith f1;

f6 on f1 f2 f3 f4 f5 f3xf1 f2xf1;

Output: standardized;

The results from testing Model 2 are summarized in the following Table:

Table 5. Model fit information and Gama coefficients for Model 2

\begin{tabular}{|c|c|}
\hline Model fit information & Model 2 \\
\hline Number of free parameters & 71 \\
\hline \multicolumn{2}{|l|}{ Loglikelihood: } \\
\hline H0 value & -3828.392 \\
\hline H0 scaling correction factor for MLR & 1.580 \\
\hline \multicolumn{2}{|l|}{ Information criteria: } \\
\hline Akaike (AIC) & 7798.783 \\
\hline Bayesian (BIC) & 8020.585 \\
\hline Sample-sized adjusted BIC & 7795.783 \\
\hline \multicolumn{2}{|l|}{ Gama coefficients of IU on: } \\
\hline $\mathrm{JS}\left(\mathrm{\gamma}_{1}\right)$ & 0.118 \\
\hline $\mathrm{JI}\left(\mathrm{\gamma}_{2}\right)$ & $0.365^{*}$ \\
\hline $\mathrm{AC}\left(\mathrm{\gamma}_{3}\right)$ & 0.130 \\
\hline $\mathrm{NC}\left(\mathrm{\gamma}_{4}\right)$ & $0.226^{* *}$ \\
\hline JST $\left(\chi_{5}\right)$ & $-0.347^{*}$ \\
\hline AC*JS $\left(\mathrm{X}_{6}\right)$ & $0.158^{* *}$ \\
\hline $\mathrm{NC} * J S\left(\mathrm{\gamma}_{7}\right)$ & -0.129 \\
\hline \multicolumn{2}{|c|}{$\begin{array}{l}\text { Legends: EP, employee performance; JS, job satisfaction; JI, job inv } \\
\text { affective commitment; NC, normative commitment; JST, job stress. } \\
{ }^{*} \text { Significant at } \mathrm{p}<0.01 \text { level. } \\
{ }^{* *} \text { Significant at } \mathrm{p}<0.05 \text { level. }\end{array}$} \\
\hline
\end{tabular}

The next step is to select one model (the best model) between Model 1 and Model 2. Model 1 has AIC of 7800.135, BIC of 8015.689, and ABIC of 7797.220 while Model 2 has AIC of 7798.783, BIC of 8020.585, and ABIC of 7795.783. Thus, if we use the AIC criterion, Model 2 is better than Model 1. By contrary, if we use the BIC criterion, Model 1 is better than Model 2. However, since Model 2 consists of all the statistically significant coefficients of Model 1 and the ABIC of Model 2 is less than that of Model 1, we are confident that Model 2 is the best fit to the sample data.

The hypothesis test results are reported based on the finalized model (Model 2) and are summarized in the following Table. 
Table 6. Summary of the hypothesis test results based on Model 2

\begin{tabular}{|c|c|c|c|c|}
\hline Hypothesis & Causal path & $\begin{array}{l}\text { Path coefficients } \\
\text { (y) }\end{array}$ & t-Value & $\begin{array}{l}\text { Hypothesis } \\
\text { supported }\end{array}$ \\
\hline H1 & $\mathrm{JS} \rightarrow \mathrm{EP}$ & 0.118 & 1.353 & No \\
\hline $\mathrm{H} 2$ & $\mathrm{JI} \rightarrow \mathrm{EP}$ & 0.365 & $2.815^{* *}$ & Yes \\
\hline H3 & $\mathrm{AC} \rightarrow \mathrm{EP}$ & 0.130 & 0.808 & No \\
\hline $\mathrm{H} 4$ & $\mathrm{NC} \rightarrow \mathrm{EP}$ & 0.226 & $2.124^{*}$ & Yes \\
\hline $\mathrm{H} 5$ & $\mathrm{JST} \rightarrow \mathrm{EP}$ & -0.347 & $2.431^{* *}$ & Yes \\
\hline $\mathrm{H} 6$ & $\mathrm{AC} * \mathrm{JS} \rightarrow \mathrm{EP}$ & 0.158 & $1.966^{*}$ & Yes \\
\hline $\mathrm{H7}$ & $\mathrm{NC} * \mathrm{JS} \rightarrow \mathrm{EP}$ & -0.129 & -1.658 & No \\
\hline $\begin{array}{l}\text { Legends: } \\
\text { commitmen } \\
{ }^{*} \text { Signifi } \\
{ }^{* *} \text { Signif }\end{array}$ & $\begin{array}{l}\text { mployee perfo } \\
\text { normative con } \\
\mathrm{p}<0.05 \text { level. } \\
\text { at } \mathrm{p}<0.01 \text { leve }\end{array}$ & $\begin{array}{l}\text { satisfaction; JI, } \\
\text { stress. }\end{array}$ & b invol & $\mathrm{AC}$, affe \\
\hline
\end{tabular}

Four of the seven hypothesized relationships were found to be statistically significant. Specifically, employee performance was most significantly influenced by job involvement $\left(\mathrm{\gamma}_{2}=0.365, p<0.01\right)$, followed by job stress $\left(\mathrm{\gamma}_{5}\right.$ $=-0.347, p<0.01)$, and normative commitment $\left(\mathrm{\gamma}_{4}=0.226, p<0.05\right)$. Also, the relationship between job satisfaction and employee performance was found to be significantly positive moderated by affective commitment $\left(\mathrm{y}_{6}=0.158, p\right.$ $<0.05$ ). Therefore, Hypotheses $\mathrm{H} 2, \mathrm{H} 4, \mathrm{H} 5$, and $\mathrm{H} 6$ are supported. However, no evidence supports that job satisfaction and affective commitment directly influence employee performance.

\section{Conclusion}

This study examined job satisfaction, job involvement, employee commitment, and job stress as predictors of employee performance. Organizational commitment is a continuous process that develops over time. Employees begin to process commitment cognitively even before they officially join a given organization based upon perceptions, the organization's reputation, and the organization's social status.

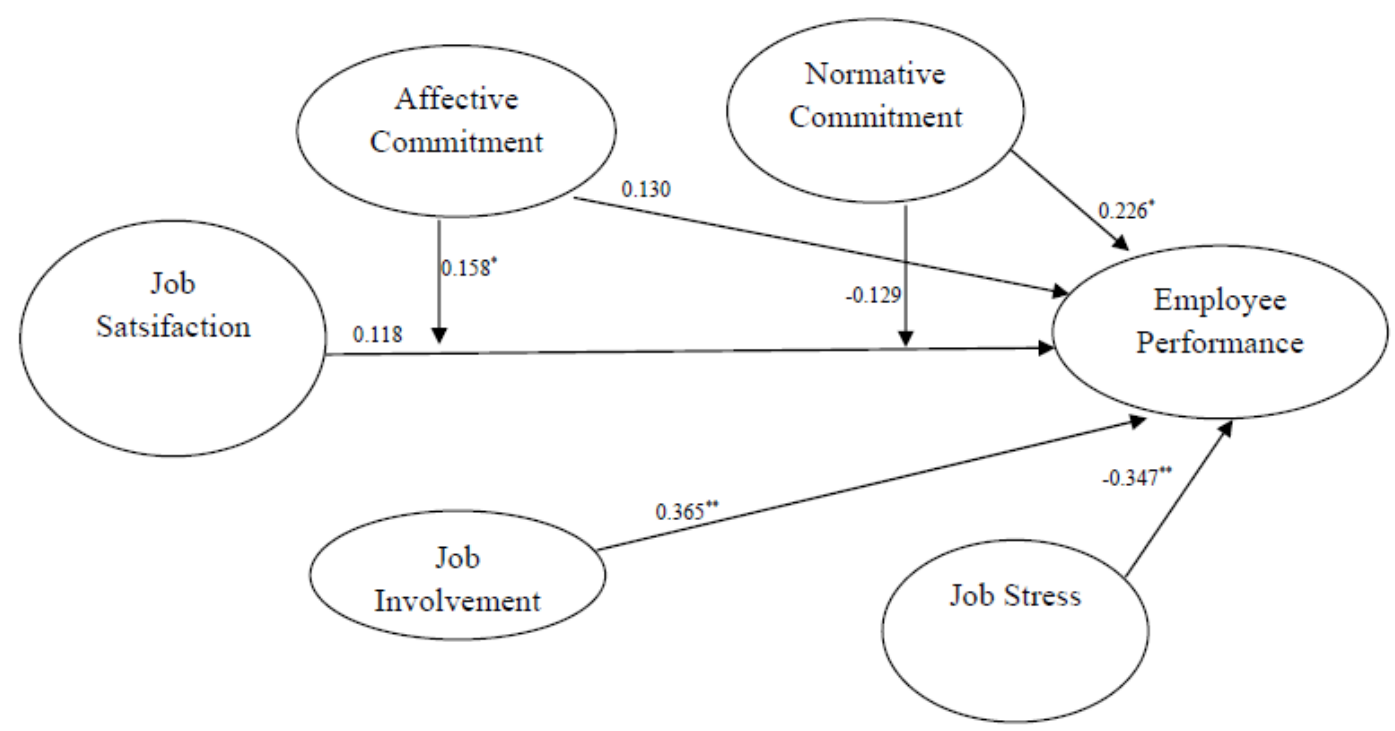

Figure 4. Structural model with specific parameters

Based on the results of the study, it was concluded that the social exchange and leader-member exchanges are the driving forces that mediate and primarily influence employee organizational commitment. Specifically, job satisfaction, job involvement, and job stress were identified as primary drivers of performance. As previous research indicated, there is consistent evidence of a relationship between perceptions of support, employee-employer indebtedness, and coworker interactions as predictors of organizational commitment. 
In the workplace environment, employees may perceive they are being treated unfairly and their personal expectations are not met. This perception may effect workplace attitudes, interactions, and perhaps even influence an employee's decision to leave or remain with the organization. Many employees have little choice in deciding whether to remain or leave an organization based on family, economics, and or other significant obligations. According to the theories, the higher the quality of workplace interactions such as collaborations and team approaches that demonstrate mutual respect could produce: pride, commitment, dedication, esteem, and employee productivity. It is assumed that the most critical factor impacting the employee-employer relationship is a vested interest based on mutual exchanges of trust, indebtedness, equality, and fairness; which, all have been identified as factors that lead to deeper bond and higher levels of organizational commitment.

Employees often have to weigh the cost of leaving versus staying with an organization. The social exchange theory proposes that employee behaviors are guided by reciprocity. Based on the results of the study, employee perception of organizational support does impact organizational commitment. In many cases, it is that perceived support that enables the employee to effectively complete required tasks and increase productivity during organizational economic and enrollment hardships. This perception of support, good or bad, can ultimately impact the quality of work being produced by the employee and the success of the organization's overall effectiveness.

Consistent with the results of study of Clay-Warner et al. (2005) on organizational justice and job satisfaction reported that similar job characteristics such as job autonomy, job complexity, and coworker support, predicted higher level of job satisfaction. Specifically, procedural justice and the level of fairness in the methods by which rewards were distributed among employees by the organization at the discretion of the supervisors directly impacted an employee's level of satisfaction. Clay-Warner et al. indicated that studies of job satisfaction could be improved by highlighting connections between job satisfaction, organizational justice, and supervisors who want satisfied workers. Employers must practice procedural justice in order to gain stronger commitment from their employees. The Makanjee et al. (2006) study on organizational commitment among diagnostic imaging radiographers also supported the outcome of this study which indicated that employees who were least satisfied with pay and opportunities for promotion were also the employees who reported low levels of job satisfaction. Few incentives were likely to lead to decreased morale and feelings of distress. This outcome demonstrated greater relevance to this study because employees with low affection and increases feelings of distress reportedly, also represented those employees who were less committed to a given organization. Freund (2005) examined commitment and job satisfaction among welfare workers. It was found that job satisfaction was not as a strong predictor of organizational commitment as career commitment. Freund found that job satisfaction was the most meaningful factor that greatly influenced withdrawal intentions of employees. Dissatisfied employees developed less commitment behavioral characteristics and were less likely to make positive investments personally and professionally in the organization. Scott et al. (2003) conducted job satisfaction research among Chinese workers and found empirical results that supported the current hypothesis identified in this study that employees who have higher levels of job satisfaction also had lower intentions to leave the organization. These intentions demonstrated behavioral characteristics that could assumingly support the notion that an employee's level of commitment to his or her organization is associated with high levels of job satisfaction.

In this study, four of the seven hypothesized relationships were found to be statistically significant. Specifically, employee performance was most significantly influenced by job involvement $\left(\mathrm{\gamma}_{2}=0.365, p<0.01\right)$, followed by job stress $\left(\mathrm{\gamma}_{5}=-0.347, p<0.01\right)$, and normative commitment $\left(\mathrm{\gamma}_{4}=0.226, p<0.05\right)$. Also, the relationship between job satisfaction and employee performance was found to be significantly positive moderated by affective commitment $\left(\mathrm{Y}_{6}=0.158, p<0.05\right)$. Therefore, Hypotheses H2, H4, H5, and H6 are supported. However, no evidence supports that job satisfaction and affective commitment directly influence employee performance.

\section{References}

Abbott, J. B., Boyd, N. G., \& Miles, G. (2006). Does type of team matter? An investigation of the relationships between job characteristics and outcomes within a team-based environment. The Journal of Social Psychology, 146(4), 485-507.

Caselman, D. T., \& Brandt, M. D. (2007). School social workers intent to stay. School Social Work Journal, 31(2), $33-48$.

Chang, J., \& Choi, J. (2007). The dynamic relation between organizational and professional commitment of highly educated research and development professional. The Journal of Social Psychology, 147(3), 299-315. 
Chen, J., SiJverworth, C., \& Hung, J. (2006). Organizational communication, job stress, organizational commitment, and job performance of accounting professionals in Taiwan and America. Leadership \& Organizational Development Journal, 27(4), 242-249.

Clay-Wamer, J., Reynolds, J., \& Roman, P. (2005). Organizational justice and job satisfaction: A test of three competing models. Social Justice Research, 18(4), 391-409.

DeFrank, R. S., \& Ivancevich, J. M. (1998). Stress on the job: An executive update.

Dwyer, D. J., \& Ganster, D. C. (1991). The effects of job demands and control on employee attendance and satisfaction. Journal of Organizational Behavior, 12, Educational and Psychological Measurements, 30(2), 607-610.

Fox, S., \& Spector, P. E. (2006). The many roles of control in a stressor-emotion theory of counterproductive work behavior. Research in Occupational Stress and Well Being, 5, 171-201.

Gerhart, B. (2005). The (affective) dispositional approach to job satisfaction: Sorting out the policy implications. Journal of Organizational Behavior, 26, 79-97.

Grandey, A. A., Cordeiro, B. L., \& Crouter, A. C. (2005). A longitudinal and multi- source test of work-family conflict and job satisfaction relationship. Journal of Occupational and Organizational Psychology, 78, 305-323.

Heller, D., Judge, T. A., \& Watson, D. (2002). The confounding role of personality and trait affectivity in the relationship between job and life satisfaction. Journal of Organizational Behavior, 23, 815-835.

Johns, R. (2005). Determinants of organizational commitment among U.S. workers. Masters Abstracts International, 43(6), 2039. (UMNI No. 1426620).

Judge, T. A., \& Illies, R. (2004). Affect and job satisfaction: A study of their relationship at work and at home. Journal of Applied Psychology, 89(4), 661-673.

Karasek, R. A. (1979). Job demands, job decision latitude, and mental strain: Implications for job redesign. Administrative Science Quarterly, 24, 285-307.

Locke, E. A. (1976). The nature and causes of job satisfaction. In Dunnette, M. D. (Ed.), Handbook of industrial and organizational psychology, (pp. 1297-1349). Chicago, IL: Rand McNally College Publishing Company.

Piccolo, R. F., Judge, T. A., Takahashi, K., Watanabe, N., \& Locke, E. A. (2005). Core self evaluations in Japan: Relative effects on job satisfaction, life satisfaction, and happiness. Journal of Organizational Behavior, 26, 965-984.

Scott, D.K., Bishop, J. W., \& Chen, X. (2003). An examination of the relationship of employee involvement with job satisfaction, employee cooperation, and intention to quit in us invested enterprise in china. The International Journal of Organizational Analysis, 11(1) 3-19.

Somech, A., \& Ron, I. (2007). Promoting organizational citizenship behavior in schools: The impact of individual and organizational characteristics. Educational Administrative Quarterly, 43(1), 38-66.

Vroom, V. H. (1964). Work and motivation. New York, NY: John Wiley \& Sons. 